\title{
Improving the Health of Patients and Communities: Evolving Practice-based Research (PBR) and Collaborations
}

Kevin Fiscella, MD, MPH

This issue illustrates how research from practice-based research networks has evolved to span a spectrum from improving patient-level care and practice quality to improving health within local and global communities. Articles address patient-level improvements (a biomarker for cardiovascular disease progression, late-onset anorexia nervosa, complementary health approaches used by patients, and patient preferences related to antibiotics for acute respiratory infections); practicelevel improvements (selection of types of fecal immunochemical tests, practice facilitation, practice registry implementation, community-based outreach, and bidirectional texting); and communitylevel improvements (primary care-public health partnership, influenza surveillance, and establishing family medicine training abroad). (J Am Board Fam Med 2017;30:562-566.)

More than 20 years ago, the Institute of Medicine (IOM), now the National Academy of Medicine, defined primary care as "The provision of integrated, accessible health care services by clinicians who are accountable for addressing a large majority of personal health care needs, developing a sustained partnership with patients, and practicing in the context of family and community." 1 The IOM defined "personal health care" to include "physical, mental, emotional, and social concerns that involve the functioning of an individual." Thus, primary care is largely charged with addressing patients health needs, which are broadly defined to include those related to family and community.

Practice-based research networks (PBRNs) are dedicated to generating the knowledge, tools, systems, and advocacy to enable primary care to improve health. Williams and Rhyne ${ }^{3}$ updated the original AHRQ definition of PBRNs ${ }^{2}$; they defined PBRNs as "A group of ambulatory practices devoted principally to the primary care of patients, and affiliated in their mission to improve the health of their patients and communities by investigating questions related to

From the Department of Family Medicine, University of Rochester Medical Center Rochester, NY.

Funding: none.

Conflict of interest: none declared.

Corresponding author: Kevin Fiscella, MD, MPH, 1381 South Ave, Rochester, NY 14620 (E-mail: Kevin_Fiscella @urmc.rochester.edu). community-based practice and to the quality of primary care, and by supporting clinicians with clinical education, methods to change practice, and opportunities to influence bealth policy" (emphasis added). ${ }^{3}$

Implicit in Williams and Rhyne's ${ }^{3}$ focus on PBRNs as "health improvement networks" is collaboration among multiple entities-for example, patients, primary care practices, communities, and other organizations-committed to improving the health of patients and their communities through research. This $7 A B F M$ issue illustrates how PBRN research has evolved to inform improvements not only at the patient and practice levels but also at the community level, often through sustained collaborations with community-based organizations.

\section{Patient-Level Improvement}

The first three articles offer more traditional PBRN research, with the potential to guide care for individual patients. National epidemiologic surveys show that anorexia nervosa manifests itself during young adulthood. ${ }^{4}$ Zayed et $\mathrm{al}^{5}$ report an exception: a malnourished 66-year-old woman with anorexia nervosa. This case report alerts clinicians in community-based practice to avoid age-related bias when diagnosing a condition with a potentially fatal trajectory.

PBRNs represent optimal laboratories for generating findings that often are generalized to 
other primary care practices. ${ }^{6}$ Cardarelli et $\mathrm{al}^{7}$ report on the NorTex PBRN Study that addresses risk factors for coronary artery calcium (CAC) and to determine whether CAC progression independently predicts cardiovascular disease-related events. Although measurement of CAC progression is not ready to be adopted into routine practice, this biomarker could be used in the future to guide informed clinician-patient decision making regarding the intensity of risk factor management.

One in 3 adults in the United States uses complementary health approaches (CHAs), and nonvitamin, nonmineral dietary supplements represent the most commonly used approach. ${ }^{8}$ Yet, most primary care clinicians do not ask about CHAs, ${ }^{9}$ and most patients do not volunteer this information if not asked. ${ }^{10}$ Handley et al ${ }^{11}$ used a validated instrument to assess CHAs among low-income participants enrolled in a diabetes self-management program. The authors also assessed how much CHAs cost patients, and then they examined the relationship between CHAs and glycemic and lipid levels. The findings may provoke primary care clinicians to ask about CHA use by patient, to elicit their patients' beliefs about CHAs and their reasons for taking them, and to discuss what is known about CHAs. Doing so may help create a shared mind-set between the clinician and patient that can guide their shared decision making. ${ }^{12}$

Acute respiratory infections are the most common reason patients seek ambulatory care in the United States. ${ }^{13}$ Despite widespread knowledge that antibiotics provide no benefit, primary care clinicians often prescribe them, largely because of their own beliefs about patients' expectations for antibiotics. ${ }^{14,15}$ Schwartz et al ${ }^{16}$ surveyed 743 patients seeking care at 6 family medicine clinics. Patients were asked about their beliefs regarding antibiotics for acute respiratory infections and their willingness to undergo a point-of-care blood test to determine their suitability for antibiotic treatment. The results are likely to surprise many primary care clinicians and potentially inform community practice.

\section{Practice-Level Improvement}

PBRN research has broadened to include a focus on improving practice quality through improved systems and processes. The next set of articles falls into this category.
The US Preventive Services Task Force includes stool tests among recommended tests used to screen for colorectal cancer. ${ }^{17}$ However, little research is available to guide practices in choosing between different types of fecal immunochemical tests (FITs). In addition to differences in costs and test accuracy-that is, sensitivity and specificity FITs differ in collection method, number of samples needed, and ease of labeling and processing of samples. ${ }^{18}$ These issues affect patient adherence and submission of adequately collected and processed samples. Pham et $\mathrm{al}^{19}$ assess patients' experiences with and preferences for 6 different FITs. Their findings, particularly if they are ultimately shown to affect the return rates of usable samples, could inform a practice's decision about which FITs to use.

The emergence of the patient-centered medical home $(\mathrm{PCMH})$ and other innovations related to primary care delivery and payment (eg, Medicare Access and CHIP Reauthorization Act of 2015 [MACRA]), are challenging primary care to transform. Yet, the process of practice transformation is often arduous, slow, and costly. ${ }^{20,21}$ Practice facilitation (PF) represents one primary vehicle for assisting practices in this process. ${ }^{22}$ Notably, PF does so by building collaborative relationships with practices, improving communication, facilitating change, and sharing resources through PBRNs. ${ }^{23} \mathrm{~A}$ critical question is how best to provide PF. Should $\mathrm{PF}$ focus generally on improving teamwork? Or should it focus on improving high-value quality metrics? Michaels et $\mathrm{al}^{24}$ report findings from a pragmatic clustered randomized trial that addressed this issue. Findings are likely to spark discussion regarding the design of PF.

Registries are foundational elements for the Chronic Care Model and the PCMH. ${ }^{25,26}$ However, little is known about factors that facilitate successful registry implementation and effective use in primary care practices. Holtrop et $\mathrm{al}^{27}$ used an innovative method, called "qualitative comparative analysis," that includes some quantitative elements to address this question among practices seeking recognition as a PCMH. Findings showed that combinations of factors, rather than any single element, were critical to implementation success. Ensuring these critical elements are present during the process of registry implementation may enhance practices' chances for success. 
Registries provide a means for identifying gaps in evidence-based care. ${ }^{28}$ However, optimal methods for providing outreach to patients to are not known. Nagykaldi et $\mathrm{al}^{29}$ aimed to evaluate a centralized approach to outreach in a rural community in Oklahoma. The project involved a unique collaboration among primary care practices, the county health department, the county hospital, and a health information exchange organization. A wellness coordinator used the community wellness registry (linked to electronic medical records via the health information exchange) to identify gaps in care and phoned patients to let them know about these gaps using protocols endorsed by their primary care clinicians. Importantly, the authors report on the return on investment from this innovative program. If further research confirms these initial findings, this program could become a model for improving quality of care within rural communities through primary care partnerships with public health and local hospitals.

Baldwin et $\mathrm{al}^{30}$ leveraged a collaboration among an academic study team, a rural primary care clinic, and a local nonprofit informatics company to use bidirectional phone texting for outreach within a rural community. Bidirectional text messaging provides a low-cost means for promoting adherence among large portions of the population. ${ }^{31}$ About 95\% of Americans currently own some type of cell phone. ${ }^{32}$ Nearly all cell phones have texting capability, although not all owners use it. Baldwin et al examined the feasibility of bidirectional texting among rural adults who needed lipid testing. The findings from their mixed-methods analysis inform clinicians interested in adopting this outreach modality.

\section{Community-Level Improvement}

The final set of articles address the newest generation of PBRN research that moves beyond a focus on improving practice quality and the health of patients within the practice to focus on improving the health of communities outside the practice, typically through sustained collaborations.

What sparks primary care clinicians to participate in research? Family physician Cynthia Wolff ${ }^{33}$ recounts the circumstances and collaborations that changed how she viewed primary care research to include a focus on community health. Her reflections underscore the power of personal relation- ships and collaborations, and provide clues for PBRNs seeking to engage busy primary care clinicians in research.

Collaboration was the theme of the IOM report "Primary Care and Public Health: Exploring Integration to Improve Population Health." ${ }^{34}$ In addition to the previously discussed article by Nagykaldi et al, ${ }^{29} 2$ other articles are relevant to this collaboration.

Pratt et $\mathrm{al}^{35}$ report on what stakeholders believe is needed to achieve such integration. Their team of investigators from primary care and public health PBRNs from 4 states conducted 40 phone interviews with key informants from these respective disciplines. Qualitative analysis revealed 2 central themes that are likely relevant to those working in primary care and public health who seek integration within their own communities.

The IOM report highlighted the importance of shared goals and shared data and analytics. Temte et $\mathrm{al}^{36}$ report on how primary care practices can take on a role traditionally performed by public health: real-time surveillance of influenza in the community. The researchers engaged a PBRN, the Wisconsin Research and Education Network, to recruit sufficient practices so that each region of the state was represented by 2 practices. Clinicians and staff received brief training in identifying eligible patients, collecting nasal specimens, and interpreting the rapid influenza detection tests. The test analyzers wirelessly transmitted anonymous results to a global wireless surveillance system. These findings are likely to be of interest to public health departments interested in early identification of influenza in communities.

Primary care collaborations to improve community health extend beyond one's local community to the global community. Evensen et $\mathrm{al}^{37}$ report on lessons learned from a multiyear collaboration between North American departments of Family Medicine and faculty at Addis Ababa University, Ethiopia, to establish the first Family Medicine residency program in Ethiopia. As a result of existing collaborations, the Ethiopian Federal Ministry of Health, Addis Ababa University, and other Ethiopian stakeholders recognized how establishing the discipline of Family Medicine in their country could facilitate the achievement of national health goals. The enumerated lessons reflect the principles for collaboration ${ }^{38}$ and are likely 
relevant to others working on similar cross-national collaborations.

Collectively, these articles exemplify the evolution of PBRNs from an exclusive focus on primary care practice to health improvement networks.

To see this article online, please go to: http://jabfm.org/content/ 30/5/562.full.

\section{References}

1. Primary care: America's health in a new era. Washington, DC: Institute of Medicine; 1996.

2. Agency for Healthcare Research and Quality. Primary care practice-based research networks: an AHRQ initiative. Created September 2012; last reviewed December 2012. Available from: https:// www.ahrq.gov/research/findings/factsheets/primary/ pbrn/index.html. Accessed June 28, 2017.

3. Williams RL, Rhyne RL. No longer simply a practicebased research network (PBRN): health improvement networks. J Am Board Fam Med 2011;24:485-8.

4. Hudson JI, Hiripi E, Pope HG, Kessler RC. The prevalence and correlates of eating disorders in the National Comorbidity Survey Replication. Biol Psychiatry 2007;61:348-58.

5. Zayed M, Garry JP. Geriatric anorexia nervosa. J Am Board Fam Med 2017;30:666-669.

6. Hickner J, Green LA. Practice-based research networks (PBRNs) in the United States: growing and still going after all these years. J Am Board Fam Med 2015;28:541-5.

7. Cardarelli R, Hall A, Rankin W. Coronary artery calcium progression is associated with cardiovascular events among asymptomatic individuals: from the North Texas Primary Care Practice-based Research Network (NorTex-PBRN). J Am Board Fam Med 2017;30:592-600.

8. Clarke TC, Black LI, Stussman BJ, Barnes PM, Nahin RL. Trends in the use of complementary health approaches among adults: United States, 2002-2012. Natl Health Stat Report 2015;(79):1-16.

9. Robinson A, McGrail MR. Disclosure of CAM use to medical practitioners: a review of qualitative and quantitative studies. Complement Ther Med 2004;12:90-8.

10. Shelley BM, Sussman AL, Williams RL, Segal AR, Crabtree BF. "They don't ask me so I don't tell them": patient-clinician communication about traditional, complementary, and alternative medicine. Ann Fam Med 2009;7:139-47.

11. Handley et al. Use of complementary health approaches among diverse primary care patients with type 2 diabetes and association with cardiometabolic outcomes from the SF Bay Collaborative Research Network (SF Bay CRN). J Am Board Fam Med 2017;30:624-631.

12. Epstein RM, Peters E. Beyond information: exploring patients' preferences. JAMA 2009;302:195-7.
13. National Center for Health Statistics. Physician Office Visits. National Ambulatory Med Care Survey: 2013. Table 11. Twenty leading principal reasons for office visits, by patient sex, United States, 2013. Atlanta: Centers for Disease Control and Prevention. Available from: https://www.cdc.gov/nchs/data/ ahcd/namcs_summary/2013_namcs_web_tables.pdf accessed 8/10/17.

14. Dempsey PP, Businger AC, Whaley LE, Gagne JJ, Linder JA. Primary care clinicians' perceptions about antibiotic prescribing for acute bronchitis: a qualitative study. BMC Fam Pract 2014;15:194.

15. McKay R, Mah A, Law M, McGrail K, Patrick DM. Systematic review of factors associated with antibiotic prescribing for respiratory tract infections. Antimicrob Agents Chemother 2016;60:4106-18.

16. Schwartz M, Hardy V, Keppel GA, et al. Patient willingness to have tests to guide antibiotic use for respiratory tract infections: from the WWAMI Region Practice and Research Network (WPRN). J Am Board Fam Med 2017;30:645-656.

17. Bibbins-Domingo K, Grossman DC, Curry SJ, et al. Screening for colorectal cancer: US Preventive Services Task Force recommendation statement. JAMA 2016;315:2564-75.

18. Lee JK, Liles EG, Bent S, Levin TR, Corley DA. Accuracy of fecal immunochemical tests for Colorectal Cancer. Systematic Review and Meta-analysis. Ann Intern Med 2014;160:171-81.

19. Pham et al. "Finding the right FIT": Rural patient preferences for Fecal Immunochemical Test (FIT) characteristics. J Am Board Fam Med 2017;30: 632-644.

20. Crabtree BF, Nutting PA, Miller WL, et al. Primary care practice transformation is hard work: insights from a 15-year developmental program of research. Med Care 2011;49(Suppl):S28-35.

21. Halladay JR, Mottus K, Reiter K, et al. The cost to successfully apply for level 3 medical home recognition. J Am Board Fam Med 2016;29:69-77.

22. Nagykaldi Z, Mold JW, Aspy CB. Practice facilitators: a review of the literature. Fam Med 2005;37: 581-8.

23. Nagykaldi Z, Mold JW, Robinson A, Niebauer L, Ford A. Practice facilitators and practice-based research networks. J Am Board Fam Med 2006;19:506-10.

24. Michaels L, Anastas T, Waddell EL, Fagnan L, Dorr DA. A randomized trial of high-value change using practice facilitation. J Am Board Fam Med 2017;30: 572-582.

25. Coleman K, Wagner E, Schaefer J, Reid R. Redefining primary care for the 21st century. Rockville, MD: Agency for Healthcare Research and Quality; 2016.

26. Rittenhouse DR, Shortell SM. The patient-centered medical home: will it stand the test of health reform? JAMA 2009;301:2038-40. 
27. Holtrop et al. What makes for successful registry implementation: A qualitative comparative analysis. J Am Board Fam Med 2017;30:657-665.

28. Phillips Jr RL, Bazemore AW, DeVoe JE, et al. A family medicine health technology strategy for achieving the triple aim for US health care. Fam Med 2015;47:628-35.

29. Nagykaldi et al. An innovative community-based model for improving preventive care in rural counties. J Am Board Fam Med 2017;30:583-591.

30. Baldwin et al. Bidirectional text messaging to improve adherence to recommended lipid testing. J Am Board Fam Med 2017;30:608-614.

31. Thakkar J, Kurup R, Laba TL, et al. Mobile telephone text messaging for medication adherence in chronic disease: a meta-analysis. JAMA Intern Med 2016;176:340-9.

32. Pew Research Center. Mobile fact sheet. January 12, 2017. Available from: http://www.pewinternet.org/ fact-sheet/mobile/. Accessed June 27, 2017.
33. Wolff C. Hooked on research: A community clinician discovers primary care research. J Am Board Fam Med 2017;30:678-680.

34. Institute of Medicine. Primary care and public health: exploring integration to improve population health. Washington, DC: National Academies Press; 2012.

35. Pratt et al. Primary care and public health perspectives on integration at the local level: A multi-state study. J Am Board Fam Med 2017;30:601-607.

36. Temte et al. New method for real time influenza surveillance in primary care: A Wisconsin research and education network (WREN) supported study. J Am Board Fam Med 2017;30:615-623.

37. Evensen et al. Family medicine in Ethiopia: lessons from a global collaboration. J Am Board Fam Med 2017;30:670-677.

38. Bedwell WL, Wildman JL, DiazGranados D, Salazar M, Kramer WS, Salas E. Collaboration at work: an integrative multilevel conceptualization. Hum Resour Manag Rev 2012;22:128-45. 